\title{
Significant release of shear energy of the North Korean nuclear test on February 12, 2013
}

subm. to Journal of Seismology

\author{
Andreas Barth \\ Karlsruhe Institute of Technology, Geophysical Institute \\ Hertzstr. 16, D-76187 Karlsruhe \\ phone: +49 721608 44507, email: a.barth@kit.edu
}

\begin{abstract}
On February 12, 2013 the Democratic People's Republic of Korea (DPRK) carried out an announced nuclear test, which was the third after tests conducted in 2006 and 2009. An important task in discriminating a man-made explosion and a natural tectonic earthquake is the analysis of seismic waveforms. To determine the isotropic and non-isotropic characteristics of the detonation source, I invert long-period seismic data for the full seismic moment tensor to match the observed seismic signals by synthetic waveforms based on a 3D earth model.

Here, I show that the inversion of long-period seismic data of the 2013 test reveals a clear explosive (isotropic) component combined with a significant release of shear energy by the double-couple part of the moment tensor. While the isotropic part of the nuclear test in 2009 was similar to that in 2013, the double-couple part was lower by a factor of 0.55 compared to the explosion in 2013 . Moreover, the ratio of the isotropic seismic moments of the 2013 and 2009 nuclear tests is $1.4 \pm 0.1$ and lower than published estimations of the yield ratio, which indicates the importance of considering the release of shear energy. The determined orientation of the double-couple fault plane is parallel to the dominating geologic fault structures NNE-SSW to NE-SW, but the calculated normal faulting mechanism does not correspond to the general tectonic strike-slip regime. Thus, explanations for the enhanced release of shear energy might be induced dip-slip motion pre-stressed by the previous test or near source damaging effects due to a changed containment of the nuclear explosion.
\end{abstract}




\section{Introduction}

According to the United States Geological Survey (USGS) the announced nuclear test on February 12, 2013 (NK2013) occurred at 02:57:51 UTC in the northeastern part of North Korea $\left(41.308^{\circ} \mathrm{N} / 129.076^{\circ} \mathrm{E}\right)$ with a magnitude of $\mathrm{m}_{\mathrm{b}}$ 5.1. The previous two tests on May 25, 2009 $\left(m_{b} 4.7\right)$ and October 9, $2006\left(m_{b} 4.3\right)$ occurred well within the calculated location error near the nuclear test site (USGS 2013, Fig. 1). Zhang \& Wen (2013) determined an epicentre 1.9 km north of the USGS location.

A common tool used for the verification of a nuclear test is the analysis of the spatial-temporal radiation pattern of radioisotopes (Fontaine et al. 2004). After the first DPRK nuclear test in 2006 (NK2006), xenon isotopes were detected at mobile and permanent noble gas stations. Backward atmospheric transport models were used to link anomalous Xe-133 concentrations to the nuclear test (Becker et al. 2010). However, for the nuclear test in 2009 (NK2009) as well as for the first weeks after the recent one, no noble gases or radionuclides were detected (Park et al. 2011; Thomson Reuter 2013). Later, on April 7, 2013 Xe-isotopes were detected at the radionuclide station in Takasaki, Japan (CTBTO 2013), which might be seen as a release due to an opening of the contained area. Since the relatively high magnitude is unlikely to be the result of conventional explosives, a planned or accidental containment of the source that could have prevented the emission of noble gases is discussed (Clery 2009).

Besides the open questions regarding the containment, an important task is the evaluation of the explosive part of the seismic source mechanism, i.e. the quantification of the isotropic component of the source radiation in contrast to the non-isotropic release of shear energy. To verify the occurrence of a man-made nuclear test conclusively, it is essential to identify the seismic event on February 12, 2013 as an explosion in order to discriminate it from a tectonic event. In this study I apply the Frequency Sensitive Moment Tensor Inversion (FMTI, Barth et al. 2007) on regional waveform data to determine the source mechanism of the North Korean event. The inversion of 
NK2013 nuclear test results in a highly isotropic source with a moment magnitude of $\mathrm{M}_{\mathrm{W}} 4.3$ and a considerable amount of released shear energy.

\section{Seismic waveform Data}

The explosive character of a seismic source can be identified by using both short- and long-period seismic signals. Figure 2 shows the raw vertical short-period signal of seismic stations within a source-receiver distance of $12^{\circ}$. The waveforms show a high signal-to-noise ratio, and the typical impulsive first arriving Pg wave supports the explosive character of the event qualitatively. The time delay of the first arrivals with increasing epicentral distance is clearly discernible. The arrival of long-period Rayleigh surface-waves can be seen at stations MDJ and BJT after $100 \mathrm{~s}$ and $300 \mathrm{~s}$, respectively.

Short-period waveform data (commonly with frequencies above $1 \mathrm{~Hz}$ ) are used to determine the ratio of compressional to shear energy radiated by evaluating the Pg/Lg ratio. For an explosion, the $\mathrm{Pg} / \mathrm{Lg}$ ratio is expected to be significantly higher than for a tectonic event, as the compressional nature of an explosion ideally does not radiate shear energy. Recent studies analysed those kind of data for the previous two nuclear tests in North Korea (NK2006 and NK2009) and determined an explosive character (Kim \& Richards 2007; Zhao et al. 2008; Shin et al. 2010; Hong 2013; Ford et al. 2009; Ford et al. 2012).

For the analysis of the February 12, 2013 nuclear test (NK2013), I use long-period waveform data ( $(\mathrm{T}=20 \mathrm{~s}$ to $75 \mathrm{~s}$ ) from 12 seismometers with source receiver distances of up to $2100 \mathrm{~km}$ and a good azimuthal distribution relative to the seismic source. The stations are part of the Global Seismograph Network (GSN), the New China Digital Seismic Network, and the Japan Meteorological Agency Seismic Network. These data were provided via the SeismiQuery system by the IRIS data center (Washington, US).

Figure 3 shows long-period signals of the NK2006, NK2009, and NK2013 at the nearest station (MDJ, China), which is located $372 \mathrm{~km}$ north of the nuclear test site. The radially and vertically 
polarised Rayleigh-waves are clearly visible on both the vertical Z and the radial NS component of the seismometer and show a similar shape for all events, indicating a similar source mechanism. Love-waves (containing shear energy) are prominent on the EW component for NK2009 (Ford et al. 2009) and NK2013. The Love-wave signal of NK2006 is covered by the seismic noise. In addition, a strong difference between the amplitude ratio of North-South (NS) to East-West (EW) component of NK2013 and NK2009 is visible. Since station MDJ is situated almost directly north of the test site, Rayleigh-waves can be seen on the NS-component, while Love-waves dominate on the EWcomponent of the seismometer. The much higher Rayleigh- to Love-waves amplitude ratio in 2013 compared to 2009 points to an additional non-explosive release of shear energy of the later nuclear test. This feature is most prominent for station MDJ, but also visible for other seismic stations (compare paragraph on results).

\section{Waveform inversion}

Seismic waves are radiated by seismic sources and modified along their travel path through the earth's structure. Thus, the analysis of a seismic source is reliant on the detailed knowledge of the earth's structure and vice versa (Sílený 2004). Long-period seismic waveform data (long wavelengths) are affected by the large-scale structure of the earth. The global knowledge of these structures makes it possible to calculate synthetic long-period waveforms. This allows the determination of an explosive character of a complex seismic source, which deviates from an ideal explosion, by using the whole waveform signal.

The moment tensor is a second order tensor that describes the complete seismic source as a point source mathematically. Moment tensor inversion is a standard tool for the determination of earthquake source mechanisms on different scales by minimising the misfit between observed and synthetic waveforms calculated generally for a $1 \mathrm{D}$ earth model (e.g. PREM by Dziewonski \& Anderson, 1981). This method strongly depends on an adequate earth model, since seismic source and earth structure shape the waveform in equal parts. Here, I apply the Frequency Sensitive 
Moment Tensor Inversion (FMTI, Barth et al. 2007) based on a 3D earth model on long-period waveform data to calculate travel path effects accurately. Synthetic waveforms are calculated using the Spectral-Element Method (Komatitsch \& Vilotte 1998). The Spectral-Element Method introduces the full complexity of the 3D earth, which includes: lateral variations in compressional wave speed, shear wave speed (e.g., Dreger \& Woods 2002) and density in the mantle (Ritsema et al. 1999), a 3D crustal model (Bassin et al. 2000), anisotropy, ellipticity, surface topography and bathymetry, as well as the effects of the oceans, rotation, and self-gravitation (Komatitsch et al. 2002). A detailed description of the $3 D$ earth model used can be found in Komatitsch \& Tromp (2002).

The FMTI performs the moment tensor inversion using a varying frequency pass-band for the seismic waveforms to find the optimum frequency range where synthetic waveforms best fit observed data with time shifts between the two allowed for optimisation (Barth et al., 2007). The global 3D earth model includes major heterogeneities in the range of $100 \mathrm{~km}$ and greater and allows the inversion of waveforms with periods larger than $20 \mathrm{~s}$ (with wavelengths of around $100 \mathrm{~km}$ ). In addition to this short-period limit, usable waveform data are also limited for long-period waves, since low magnitude seismic sources provide amplitudes higher than the seismic noise level only at waves of rather short periods of about $50 \mathrm{~s}$. Thus, especially for weak seismic events, which are recorded in regional distances up to $3000 \mathrm{~km}$, the FMTI makes it possible to find wave-parts individually that contain enough information to invert for the seismic source (Barth \& Wenzel 2010). Applying a sufficient earth model and the optimum frequency pass-band, the explosive component as well as the moment magnitude $\mathrm{M}_{\mathrm{W}}$ of the seismic source can be determined reliably. Moment tensor inversions have been used before to analyse explosive sources typically for 1D earth models (e.g. Dreger \& Woods 2002, Shin et al. 2010). Figure 4 compares synthetic waveforms calculated for a pure isotropic (explosive) source for a 1D and 3D global earth model. This example shows that the long-period waveforms (here periods of $32 \mathrm{~s}$ to $43 \mathrm{~s}$ are shown) calculated for the 1D PREM model (Dziewonski \& Anderson, 1981) and the 3D model compiled by Komatitsch et al. 
(2002) result in identical shapes for the first arriving wave-package. Looking at later arrivals (after $200 \mathrm{~s}$ ) the heterogeneous 3D model introduces refracted and reflected waveforms that were not existent in the $1 \mathrm{D}$ calculations. Calculating waveforms for periods down to $20 \mathrm{~s}$ results even in stronger differences of the waveform shape.

After Gilbert \& Dziewonski (1975) the elements of the symmetric seismic moment tensor $\bar{M}$ are given as:

$$
\overline{\boldsymbol{M}}=\left(\begin{array}{lll}
M_{r r} & M_{r \theta} & M_{r \Phi} \\
M_{r \theta} & M_{\theta \theta} & M_{\theta \Phi} \\
M_{r \Phi} & M_{\theta \Phi} & M_{\Phi \Phi}
\end{array}\right)
$$

with the seismic moment:

$$
M_{0}=\sqrt{\frac{1}{2} \cdot\left(\sum M_{i j}\right)^{2}}
$$

To determine the explosive part of a seismic source, the seismic moment tensor $\bar{M}$ has to be decomposed in its isotropic $\overline{\boldsymbol{M}}_{\boldsymbol{I}}$ and deviatoric $\overline{\boldsymbol{M}}_{\text {dev }}$ part (Jost \& Hermann 1989; Knopoff \& Randall 1970):

$$
\overline{\boldsymbol{M}}=\overline{\boldsymbol{M}}_{\boldsymbol{I}}+\overline{\boldsymbol{M}}_{\mathrm{dev}}=\left(\begin{array}{ccc}
m_{\text {iso }} & 0 & 0 \\
0 & m_{\text {iso }} & 0 \\
0 & 0 & m_{\text {iso }}
\end{array}\right)+\left(\begin{array}{ccc}
\lambda_{1} & 0 & 0 \\
0 & \lambda_{2} & 0 \\
0 & 0 & \lambda_{3}
\end{array}\right),
$$

with the eigenvectors $\left|\lambda_{1}\right| \geq\left|\lambda_{2}\right| \geq\left|\lambda_{3}\right|$. Then the isotropic seismic moment can be determined by

$$
M_{I}=\sqrt{\frac{1}{2} \cdot 3 \cdot(\operatorname{tr}(\overline{\boldsymbol{M}}) / 3)^{2}}=\sqrt{\frac{3}{2} m_{\text {iso }}^{2}},
$$

and hence the isotropic part of the full moment tensor is given by

$$
I S O=\frac{M_{I}}{M_{0}}
$$

Then the deviatoric moment tensor consists of a double-couple (DC) and a compensated linear vector dipole (CLVD) part. The latter is given by

$$
C L V D=(1-I S O) \cdot 2 \cdot\left|\frac{\lambda_{3}}{\lambda_{1}}\right| .
$$


The double couple mechanism describes the simplest and most common tectonic earthquake source model that is a pure slip on an arbitrarily oriented fault plane. More complex sources contain higher CLVD and isotropic parts. It is well known that moment tensor elements are strongly coupled, especially for earthquakes with shallow hypocentres. For non-isotropic sources this may lead to similar waveforms for a pure double couple source and the general deviatoric moment tensor (Henry et al. 2002; Bukchin et al. 2010). In case of the inversion for the full moment tensor $\bar{M}$ a strong coupling of the CLVD and isotropic parts is apparent (Kanamori \& Given 1981; Kawakatsu 1996). Thus, to study the explosive character of the man-made, shallow North Korean nuclear tests, I evaluate the well constrained pure double couple part, that is

$$
D C=1-I S O-C L V D,
$$

with DC, CLVD and ISO ranging from 0 to 1 (or from 0 to 100 when given in percent).

\section{Results}

The FMTI evaluates the source mechanism and seismic moment for a sliding $8 \mathrm{mHz}$ wide frequency band between $12 \mathrm{mHz}$ and $46 \mathrm{mHz}$ and a shallow source with a hypocentral depth of $1 \mathrm{~km}$. Figure 5 shows $D C$ as a function of the frequency pass-band for the 2006, 2009, and 2013 North Korean nuclear tests. The analysis reveals a significant difference between NK2009 and NK2013 that DC is considerably lower for NK2009 than for NK2013 regarding frequency passbands above a central frequency of $23 \mathrm{mHz}$. To achieve stable and comparable inversion results of both events, frequency pass-bands with a resulting data variance $\varepsilon<0.5$ are chosen (Barth et al. 2007):

$$
\varepsilon=\left(x_{o}-x_{s}\right)^{2} / x_{o}^{2},
$$

with observed waveforms $\boldsymbol{x}_{\boldsymbol{o}}$ and synthetic waveforms $\boldsymbol{x}_{\boldsymbol{s}}$. This variance level is reached for frequency pass-bands above a central frequency of $24 \mathrm{mHz}$, which corresponds to a pass-band from $20 \mathrm{mHz}$ to $28 \mathrm{mHz}$ (Fig. 5). Higher data variances at lower frequencies are due to a worse signal-to- 
noise ratio. For NK2009 DC varies between 20\% and 40\%, whereas for NK2013 it is between 44\% and 58\%, indicating a higher release of shear energy for the latter. Because of its low signal-tonoise-ratio, DC calculated for NK2006 varies strongly and will not be interpreted.

Enhancing the frequency pass-band for the final moment tensor inversion from $20 \mathrm{mHz}$ to higher frequencies results in better data fits (lower variances) with an optimum at the upper limit of $36 \mathrm{mHz}$. Using the limits of this best fitting frequency pass-band from $20 \mathrm{mHz}$ to $36 \mathrm{mHz}$, both resulting source mechanisms show a good agreement between observed and synthetic data with variances $\varepsilon$ around 0.4 (Fig. 6). Time shifts for the adapted waveforms are small and change only slightly between the two events. The elements of the full moment tensor are given in Table 1.

The strong signal at the end of the transverse component T of station BJT in 2013 (Fig. 6b) results from a tectonic $\mathrm{M}_{W} 4.5$ earthquake in Xizang/China (3171 km distance to the North Korean test site) that occurred on February 12, 2013, 02:55:14 UTC just 2:37 min before the nuclear explosion. On other seismometer components the earthquake signal is cut off or not visible due to its lower amplitudes. The signal at the very beginning of the vertical component $\mathrm{Z}$ of station SSE is due to long period seismic noise and does not result from the Xizang earthquake. Thus, those earthquake signals could not obscure the long-period signals of NK2013 and were not able to influence the DC determination of this third nuclear test of North Korea.

Isotropic parts are high and range between 50\% and 52\% for both events (Fig. 6). Also, the source mechanism of the double couple part is similar for both nuclear tests with normal faulting mechanisms striking NNE-SSW to NE-SW. All transverse components for NK2013 show equal or larger amplitudes compared to the ones from NK2009 (stations MDJ, MAY, TAT, XAN, BJT, HIA). These high amplitude shear waves are the reason for the higher DC of NK2013. DC for NK2009 and NK2013 is $27.3 \%$ and $49.7 \%$, respectively, and confirm the results of the frequency dependent analysis (Fig. 5). Accordingly, DC of NK2009 is lower than in NK2013 by a factor of 0.55.

The determination of the seismic moment tensor and the different scalar moments depends on an accurate earth model and sufficient signal-to-noise ratio (SNR) of the inverted data. To analyse the 
influence of seismic noise on the determination of the DC I use forward calculated synthetic waveforms of a pure explosion for 3D earth model (Fig. 4) and add random white noise with different maximum amplitudes. The resulting waveforms are inverted for the $20 \mathrm{mHz}$ to $36 \mathrm{mHz}$ frequency pass-band and $D C$ is calculated. Figure 7 shows averaged $D C$ values and standard deviations that result from 100 noise calculations for each SNR. Both values decrease with decreasing SNR. A moderate SNR ratio down to five introduces only a minor double-couple mechanism $(D C<13 \pm 9 \%)$ to the original isotropic source, which is always below the result for NK2009. Even for a SNR of three the average DC is below 25\%, showing that low amplitude seismic noise has only a minor influence on the inversion result.

The deconvolution of the seismic moment tensor allows the separation of the isotropic seismic moment $M_{I}$ (Eqn. 4). Patton \& Taylor (2011) discussed how the isotropic moment tensor $M_{I}$ might be related to yield. They suggested that the observed isotropic moment (resulting from the measurement of volume change in the cavity) also incorporates effects of cavity formation and material damage, which may introduce radiation of shear energy. I use the FMTI to analyse the variability of the seismic moment of NK2013 and NK2009. Figure 8 shows the full seismic moment $M_{0}$ and the isotropic moment $M_{I}$ within the best fitting frequency pass band between $20 \mathrm{mHz}$ to $36 \mathrm{mHz}$ using $8 \mathrm{mHz}$ wide pass-bands. A general trend shows increasing moments for the inversion of higher frequencies, indicating a higher energy release. In contrast to $M_{0,2013}$ the trend for $M_{0,2009}$ shows a clear decrease of moment at a central frequency of $25 \mathrm{mHz}$ that corresponds well with a decrease of $D C$ (Fig. 8). However, the isotropic moments $M_{I, 2013}$ and $M_{I, 2009}$ are quite stable and only increasing slightly with frequency. Over the frequency range shown in Fig. 8, the ratio of $M_{I, 2013}$ and $M_{I, 2009}$ can be determined to $1.4 \pm 0.1$, which gives an indication for a higher yield of NK2013 compared to NK2009. However, high frequency amplitude ratios of the two nuclear tests indicate a factor of 2.5 (BGR 2013, compare Fig. 3). Zhang \& Wen (2013) estimated a yield ratio of $1.7 \pm 1.9$ based on Lg-magnitudes and burial depths of $430 \mathrm{~m}$ and $610 \mathrm{~m}$, respectively. These results show the 
strong influence of radiated shear energy on the seismic moment $M_{0}$ and thus on the moment magnitude. Therefore, estimating the yield of a nuclear test should always consider the nonisotropic part of the seismic moment tensor.

To analyse the reliability of the source mechanism and the obtained high DC for NK2013, I apply a jackknife test. For this purpose the FMTI is performed excluding pairs of seismic stations as well as single ones for separate inversion runs (Fig. 9). In additional to the number of 12 recording stations, 66 different combinations of station pairs are possible. Accordingly, 78 inversion runs are performed in total. This statistical test shows stable NE-SW striking normal faulting source mechanisms for all sub-data sets of NK2013 and DC varying between 32\% and 55\% with an average of $45.4 \%$. This shows that the high DC-content of NK2013 does not depend on single stations, but results for all realisations in values $D C>27.3 \%$, which was determined for NK2009. Variances $\varepsilon$ for the jackknife test vary between 0.30 and 0.47 , which is in the order of the value for the inversion including all station data.

Additionally, I use these station combinations to analyse the stability of $D C$ in dependance of the frequency pass-band. Figure 10 shows the DC ratio of the of NK2009 and NK2013 averaged over all station combinations. Regarding variances $\varepsilon<0.5$ the ratio varies between 0.43 and 0.92 , with standard deviations of around 0.15 and an average value of 0.60 that confirms the value of 0.55 obtained for the whole dataset inverted for the best fitting frequency pass-band.

\section{Discussion}

The existence of shear energy radiated by nuclear explosions was observed previously (e.g. Stevens \& Baker 2009) and cannot be explained by mapping seismic noise into the source mechanism (Fig. 7). Especially well contained underground explosions, which are thought to have a high coupling to the surrounding material, might radiate shear waves due to block motions, spall, damage or tectonic triggering (Baker et al. 2010). Block motion movements on pre-existing faults allow discrete (near-)vertical displacements along existing joints and faults (Heuzé et al. 1991). In 
contrast to tectonic triggering, they might occur due to a pre-stressing of the affected volume possibly by previous nuclear explosions (Pattton 1991). Small explosions in water filled cavities may also radiate shear waves without any damage of material (Baker et al. 2010). In this case, the generation of those wave occurs near the explosion source; probably due to oscillations of an asymmetrical shaped cavity. Patton \& Taylor (2011) found that a non-isotropic radiation pattern for long-period waves might be a contribution from material damage in the source medium. Observed normal faulting mechanisms might be a consequence of slapdown of spalled layers.

The latest two North Korean nuclear tests in 2009 and 2013 occurred in close vicinity and were probably well contained (and therefore coupled to the surrounding material), since the both of them did not show any significant release of radioisotopes. Nevertheless, this study shows that only the nuclear explosion in 2013 did release a major part of shear energy, while, corresponding to the results of Shin et al (2010), NK2009 did not. Moreover, the obtained strike of the potential fault planes of the shear energy release for both tests correlates well with the observed orientation of fault systems in the region, which are dominantly NE-SW to NNE-SSW (Şengör \& Natal'in 1996). However, the regional stress regime is rather strike-slip with orientations of the maximum horizontal stress around $70^{\circ}$ to $74^{\circ}$ East in eastern China as well as in South Korea (Barth \& Wenzel 2010; Rhie \& Kim 2010) and up to $90^{\circ}$ East in NE South Korea (Park et al. 2007; Jin \& Park 2006) and not consistent with the normal faulting mechanism observed for both nuclear tests. West of this strike-slip regime, a region of normal faulting is apparent in the Yellow Sea, and this is interpreted as a collision belt between the North and South China blocks (Hong \& Choi 2012). Another local anomaly is present offshore of eastern South Korea, where a reverse faulting structure is adjoining, suggesting reverse activation (Choi et al. 2012). Anyhow, a pure tectonic triggering, which would reflect both regime and fault orientation, can be ruled out. This is supported by the fact that only NK2013 and not NK2009 released an considerable amount of shear energy, as would be expected by a tectonic release according to Patton (1991). 


\section{Conclusion}

In this study I showed that the isotropic and non-isotropic double-couple part of the seismic radiation pattern of the North Korean nuclear test in 2009 and 2013 can be determined using 12 regional seismometer stations with distances up to $2100 \mathrm{~km}$. I used the Frequency Sensitive Moment tensor Inversion (FMTI) to obtain the best fitting frequency pass-band of $20 \mathrm{mHz}$ to $36 \mathrm{mHz}$ (periods $28 \mathrm{~s}$ to $50 \mathrm{~s}$ ). While both tests show a strong isotropic (explosive) component of around $50 \%$, the part of double-couple radiation (i.e. release of shear energy) was significantly higher in 2013 (49.7\%) than in 2009 (27.3\%) and also the isotropic seismic moment was increased by a factor of $1.4 \pm 0.1$. Anyhow, the source mechanism of both nuclear tests are similar normal faulting mechanisms, striking NNE-SSW to NE-SW. Together with the fact that both nuclear tests did not release radioisotopes directly after the explosion and a well contained source can be assumed, at least two principle scenarios might be possible to explain those difference in the source radiation.

On one hand the enlarged shear wave radiation of the nuclear test 2013 might be attributed to a dipslip block motion within an originally tectonic strike-slip regime that was locally pre-stressed by the previous test in 2009. Alternatively, the containment of the nuclear source could have been changed operationally for the nuclear test in 2013 compared to 2009. Thus, in 2013 material damage could have occurred that released the observed shear energy. Geomechanic modelling might give insights into the effects of those scenarios and help to understand the difference of the North Korean nuclear tests in 2009 and 2013.

\section{Acknowledgements}

I thank Friedemann Wenzel and Joachim Ritter for the critical review of the manuscript and fruitful discussions, as well as three anonymous reviewers for their constructive remarks. I'm very grateful for linguistic assistance from James Daniell and Susan Brink. Data were processed with SeismicHandler (Stammler 1993) and figures were made using GMT (Wessel \& Smith 1998). 


\section{References}

Baker GE, Xu H, Stevens JL (2010) Generation of Shear Waves from Explosions in Water-Filled Cavities. Bull Seism Soc Am 100:1196-1210

Barth A, Wenzel F (2010) New constraints on the intraplate stress field of the Amurian plate deduced from light earthquake focal mechanisms. Tectonophysics 482:160-169

Barth A, Wenzel F, Giardini D (2007) Frequency sensitive moment tensor inversion for light to moderate magnitude earthquakes in eastern Africa. Geophys Res Lett 34:L15302

Bassin C, Laske G, Masters G (2000) The Current Limits of Resolution for Surface Wave Tomography in North America. EOS Trans AGU 81:F897

Becker A, Wotawa G, Ringbom A, Saey PRJ (2010) Backtracking of Noble Gas Measurements Taken in the Aftermath of the Announced October 2006 Event in North Korea by Means of PTS Methods in Nuclear Source Estimation and Reconstruction. Pure Appl Geophys 167:581-599

BGR (2013) BGR registriert vermutlichen dritten nordkoreanischen Kernwaffentest. http://www. bgr.bund.de/DE/Themen/Erdbeben-Gefaehrdungsanalysen/Seismologie/Kernwaffenteststopp/ Kernexplosionen/Kernex/nordkorea_20130212.html?nn=1562510. Accessed 12 December 2013

Bukchin B, Clévédé E, Mostinskiy A (2010) Uncertainty of moment tensor determination from surface wave analysis for shallow earthquakes. J Seismol 14:601-614

Choi H, Hong TK, He X, Baag CE (2012) Seismic evidence for reverse activation of a paleo-rifting system in the East Sea (Sea of Japan). Tectonophysics 572-573:123-133

Clery D (2009) Verification Experts Puzzled Over North Korea's Nuclear Test. Science 324:1499

CTBTO (2013) CTBTO detects radioactivity consistent with 12 February announced North Korean nuclear test. Press release, April 7, 2013

Dreger D, Woods B (2002) Regional distance seismic moment tensors of nuclear explosions. Tectonophysics 356:139-156

Dziewonski AM, Anderson DL (1981) Preliminary reference Earth model. Phys Earth Plant Int 25:297-356 
Fontaine JP, Pointurier F, Blanchard X, Taffary T (2004) Atmospheric xenon radioactive isotope monitoring. J Environ Radiat 72:129-135

Ford SR, Dreger DS, Walter WR (2009) Source analysis of the Memorial Day explosion, Kimchaek, North Korea. Geophys Res Lett 36, L21304

Ford SR, Walter WR, Dreger DS (2012) Event Discrimination using Regional Moment Tensors with Teleseismic-P Constraints. Bull Seism Soc Am 102:867-872

Gilbert F, Dziewonski AM (1975) An application of normal mode theory to the retrieval of structural parameters and source mechanisms from seismic spectra. Philos Trans R Soc London 278:187-269

Henry C, Woodhouse JH, Das S (2002) Stability of earthquake moment tensor inversions: Effect of the double-couple constraint. Tectonophysics 356:115-124

Heuzé FE, Butkovich TR, Walton OR, Maddix DM (1991) Explosion phenomenology in jointed rocks: new insights. In: Taylor SR, Patton HJ, Richards PG (eds) Explosion Source Phenomenology, Geophysical Monograph 65. American Geophysical Union, Washington DC, pp $253-260$

Hong TK (2013) Seismic discrimination of the 2009 North Korean nuclear explosion based on regional source spectra. J Seismol 17:753-769

Hong TK, Choi H (2012) Seismological constraints on the collision belt between the North and South China blocks in the Yellow Sea. Tectonophysics 570-571:102-113

Jin SG, Park PH (2006) Crustal stress and strain energy density rates in South Korea deduced from GPS observations. Terr Atmos Ocean Sci 17:169-178

Jost ML, Hermann RB (1989) A Student's Guide to and Review of Moment Tensors. Seism Res Lett 60:37-57

Kanamori, H, Given JW (1981) Use of long-period surface waves for rapid determination of earthquake-source parameters. Phys Earth Plant Int 27:8-31

Kawakatsu H (1996) Observability of the isotropic component of a moment tensor. Geophys J Int 
126:525-544

Kim W, Richards PG (2007) North Korean Nuclear Test: Seismic Discrimination at Low Yield. EOS Trans AGU 88:158

Knopoff L, Randall MJ (1970) The compensated linear-vector: a possible mechanism for deep earthquakes. J Geophys Res 75:4957-4963

Komatitsch D, Ritsema J, Tromp J (2002) The Spectral-Element Method, Beowulf Computing, and Global Seismology. Science 298:1737-1742

Komatitsch D, Tromp J (2002) Spectral-element simulations of global seismic wave propagation II. Three-dimensional models, oceans, rotation and self-gravitation Geophys J Int 150:303-318

Komatitsch D, Vilotte JP (1998) The spectral element method: An efficient tool to simulate the seismic response of 2D and 3D geological structures. Bull Seism Soc Am 88:368-392

Park J, von Frese RRB, Grejner-Brzezinska DA, Morton Y, Gaya-Pique LR (2011) Ionospheric detection of the 25 May 2009 North Korean underground nuclear test. Geophys Res Lett 38:L22802

Park JC, Kim W, Chung TW, Baag CE, Ree JH (2007) Focal mechanisms of recent earthquakes in the Southern Korean Peninsula. Geophys J Int 169:1103-1114

Patton HJ (1991) Seismic moment estimation and the scaling of the long-period explosion source spectrum. In: Taylor SR, Patton HJ, Richards PG (eds) Explosion Source Phenomenology, Geophysical Monograph 65. American Geophysical Union, Washington DC, pp 171-183

Patton HJ, Taylor SR (2011) The apparent explosion moment: Inferences of volumetric moment due to source medium damage by underground nuclear explosions. J Geophys Res 116:B03310

Rhie J, Kim S (2010) Regional moment tensor determination in the southern Korean Peninsula. Geosci J 14:329-333

Ritsema J, van Heijst HJ, Woodhouse JH (1999) Complex shear wave velocity structure imaged beneath Africa and Iceland. Science 286:1925-1928

Şengör AMC, Natal'in BA (1996) Paleotectonics of Asia: fragments of a synthesis. In: Yin A, 
Harrison TM (eds) The tectonic evolution of Asia. Cambridge University Press, Cambridge, pp 486-640

Shin, JS, Sheen DH, Kim, G (2010) Regional observations of the second North Korean nuclear test on 2009 May 25. Geophys J Int 180:243-250

Sílený J (2004) Regional moment tensor uncertainty due to mismodeling of the crust. Tectonophysics 383:133-147

Stammler K (1993) SeismicHandler: Programmable multichannel data handler for interactive and automatic processing of seismological analyses. Comput Geosci 19:135-140

Stevens JL, Baker GE (2009) Seismic wave generation by a nonisotropic explosion source. J Geophys Res 114:B12302

Thomson Reuters (2013) No "smoking gun" from North Korean nuclear test. http://www.reuters. com/article/2013/03/12/us-nuclear-northkorea-test-ban-idUSBRE92B0J220130312. Accessed 4 July 2013

U.S. Geological Service (2013) M5.1 North Korea Nuclear Explosion of 12 February 2013. http://earthquake.usgs.gov/earthquakes/eqarchives/poster/2013/NorthKorea.pdf. Accessed 4 July 2013

Wessel P, Smith WHF (1998) New, improved version of Generic Mapping Tools released. EOS Trans AGU 79:579

Zhang M, Wen L (2013) High-precision location and yield of North Korea's 2013 nuclear test. Geophys Res Lett 40:2941-2946

Zhao LF, Xie XB, Wang WM, Yao ZX (2008) Regional Seismic Characteristics of the 9 October 2006 North Korean Nuclear Test. Bull Seism Soc Am 98:2571-2589 
Table 1

Moment tensor elements (in $10^{16} \mathrm{Nm}$ ) after Gilbert \& Dziewonski (1975) of the final MTI for the nuclear tests in 2009 and 2013 for the optimum frequency pass-band from $20 \mathrm{mHz}$ to $36 \mathrm{mHz}$ (periods 28 s to $50 \mathrm{~s}$ ).

\begin{tabular}{|l|l|l|l|l|l|l|}
\hline & $\mathrm{M}_{\mathrm{rr}}$ & $\mathrm{M}_{\theta \theta}$ & $\mathrm{M}_{\Phi \Phi}$ & $\mathrm{M}_{\mathrm{r} \theta}$ & $\mathrm{M}_{\mathrm{r} \Phi}$ & $\mathrm{M}_{\theta \Phi}$ \\
\hline 2009 & -0.978 & 1.83 & 1.89 & 0.673 & 0.141 & 0.555 \\
\hline 2013 & -1.81 & 2.88 & 3.86 & 0.105 & 0.230 & 1.66 \\
\hline
\end{tabular}

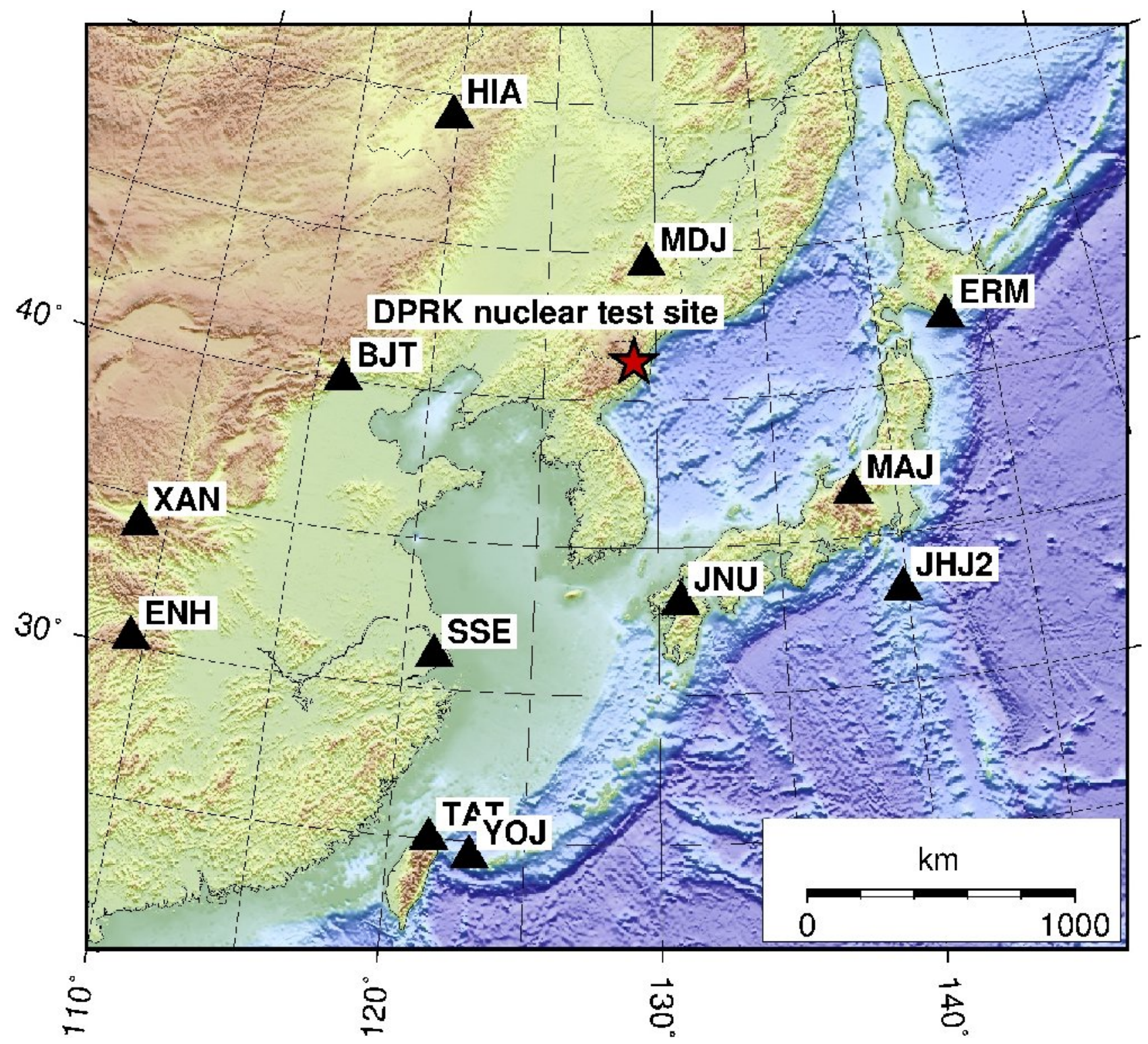

Figure 1: Topographic map of Korea and adjacent areas showing the location of the DPRK nuclear test site (red star). Triangles indicate permanent seismic stations used in this study. 


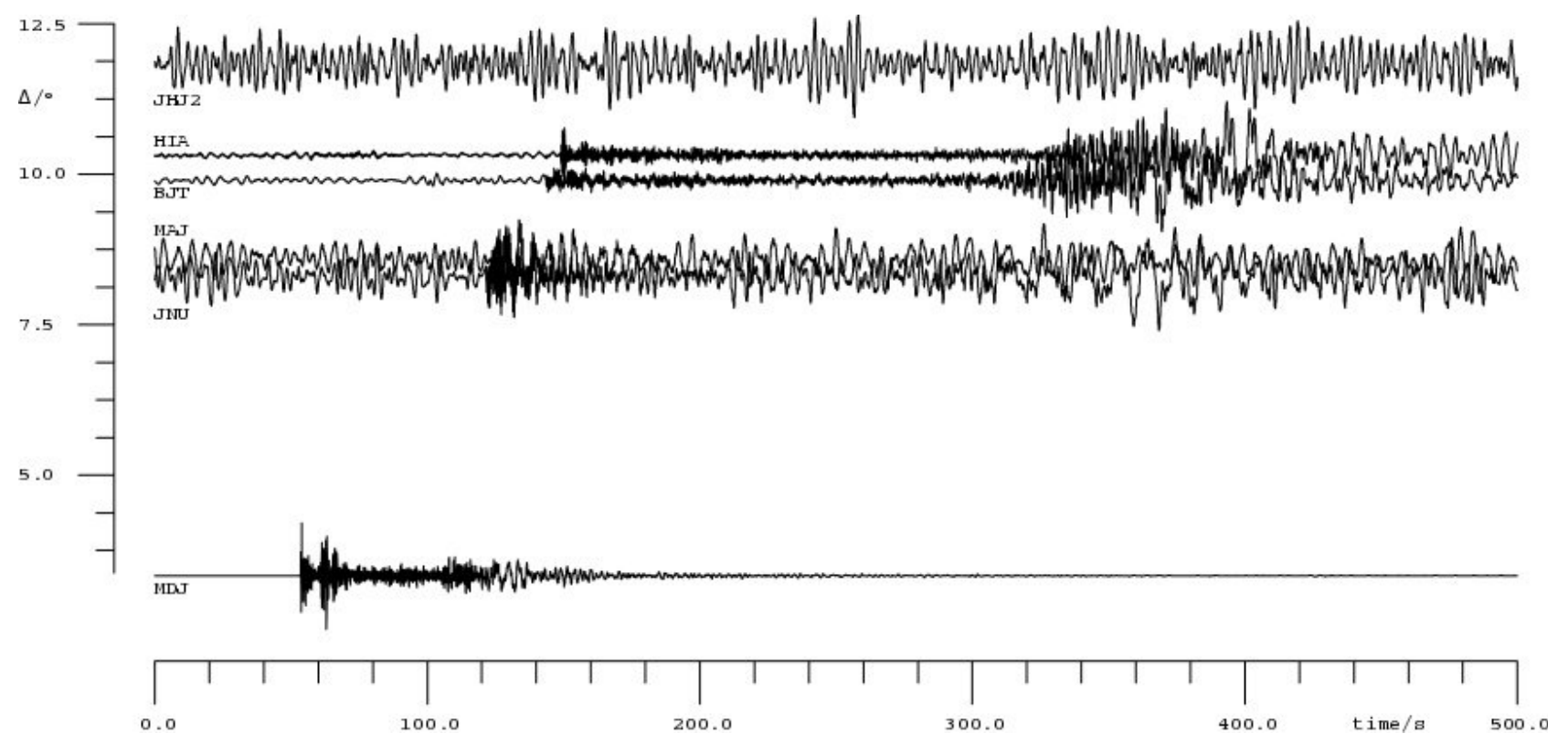

Figure 2: Raw vertical waveform traces for the North Korean nuclear test 2013 from permanent seismic stations used for moment tensor inversion. The linear trend of the raw waveforms is removed and amplitudes are normalised. The time axis starts at the event origin.

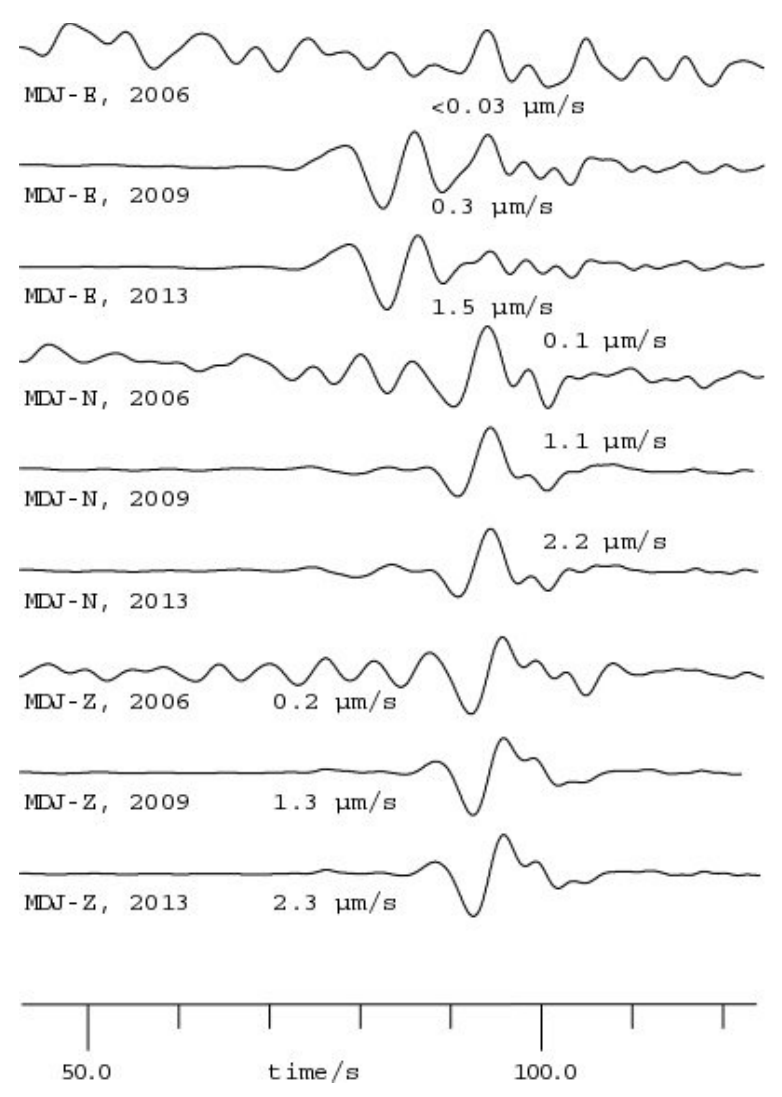

Figure 3: Long period seismic waveforms of the nearest seismic station MDJ (372 km north of the test site) for vertical and horizontal seismometer components (N: North-South, E: East-West). Low-pass filtered for $0.1 \mathrm{~Hz}$. Annotations give the maximum ground velocity per trace. 


\section{NORTH KOREA SYNTHETIC EXPLOSION}

Date: Time: Lat: 41.30 Long: 129.00 Depth: 1

Plane (strike/dip/slip) NP1: 180/45/ 90 NP2: 0/45/90

Frequence range (Hz): .0230-.0310 Variance: 0.137 Mw: 5.0

$0 \%$ double couple

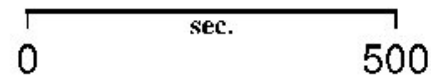

$100 \%$ isotropic

$\mathbf{Z}$

$\mathbf{R}$
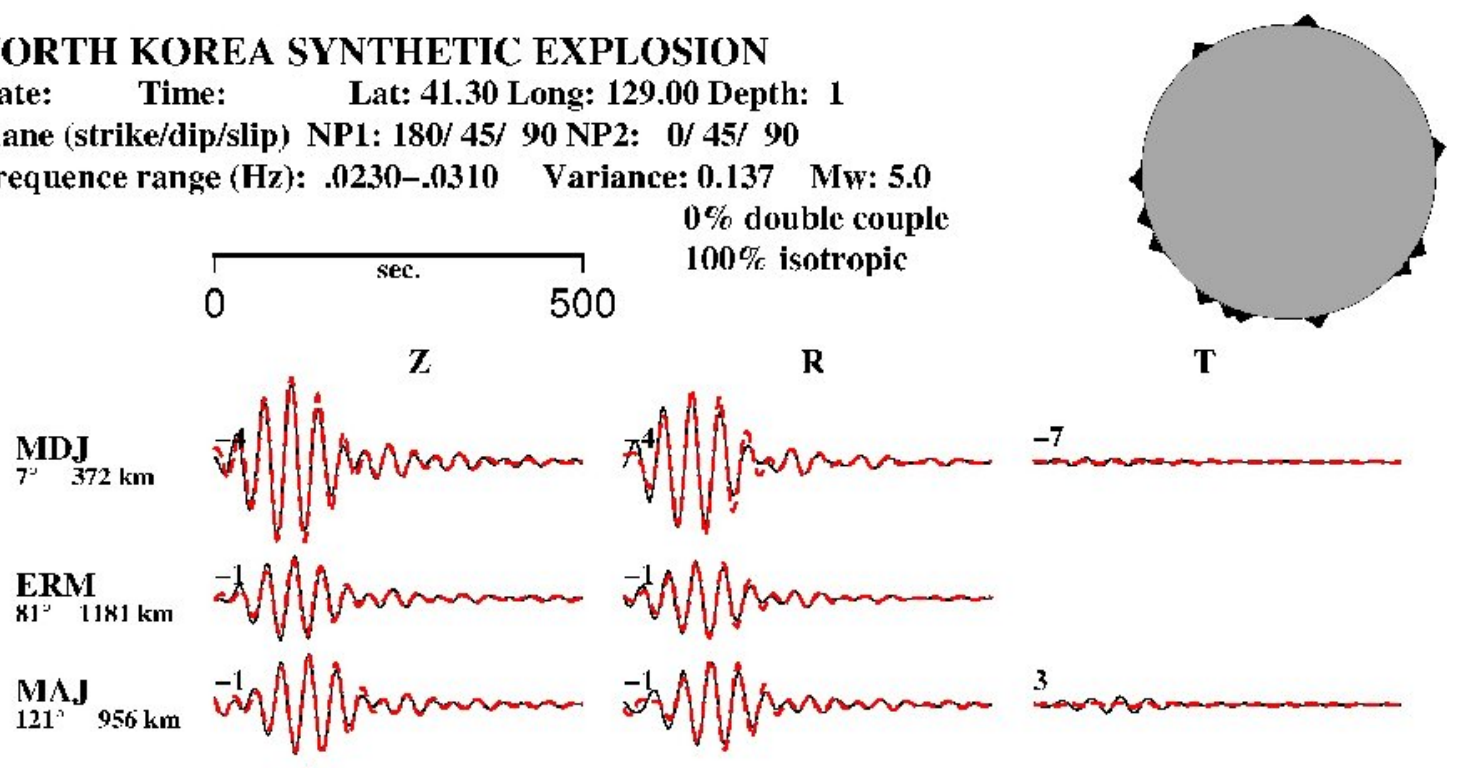

$\mathbf{T}$
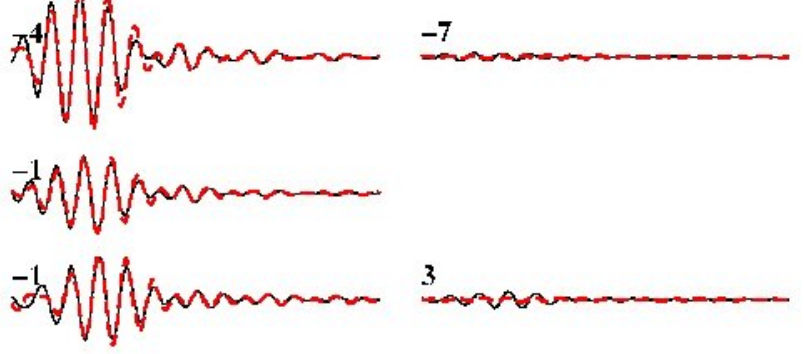

3

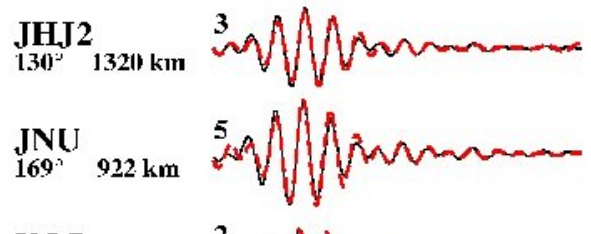

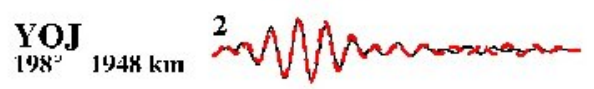

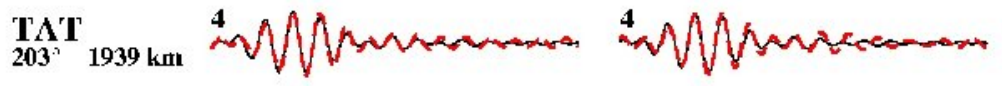

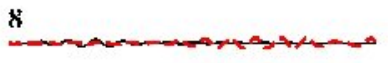

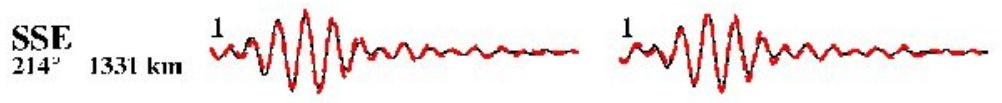

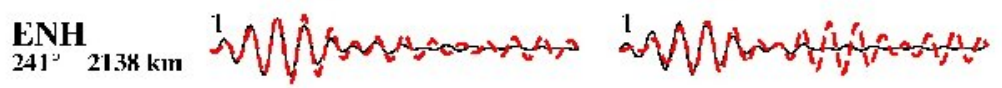

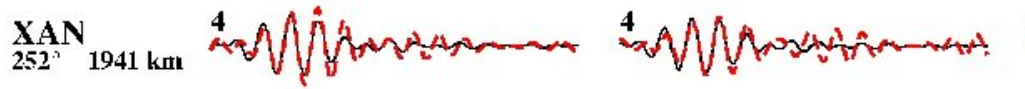
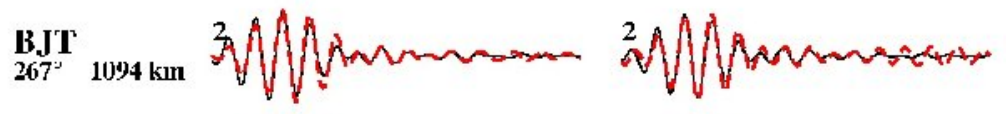

HIA $1144 \mathrm{~km}$ of

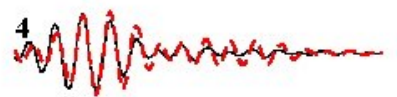

8

8

Figure 4: Forward calculation of synthetic waveforms of a pure explosion source at the North Korean test site for the frequency pass-band from $23 \mathrm{mHz}$ to $31 \mathrm{mHz}$ (periods $32 \mathrm{~s}$ to $43 \mathrm{~s}$ ). Black solid lines correspond to calculations of the vertical, radial, and transverse components $(\mathrm{Z}, \mathrm{R}, \mathrm{T})$ based on the 1D standard Earth model PREM. Red dashed lines result from 3D calculations. Triangles around the source mechanism indicate station azimuths. Below the station name azimuth and epicentral distance is given. Amplitudes are plotted normalised to the maximum of each station. Numbers above each trace correspond to a time shift in seconds. 


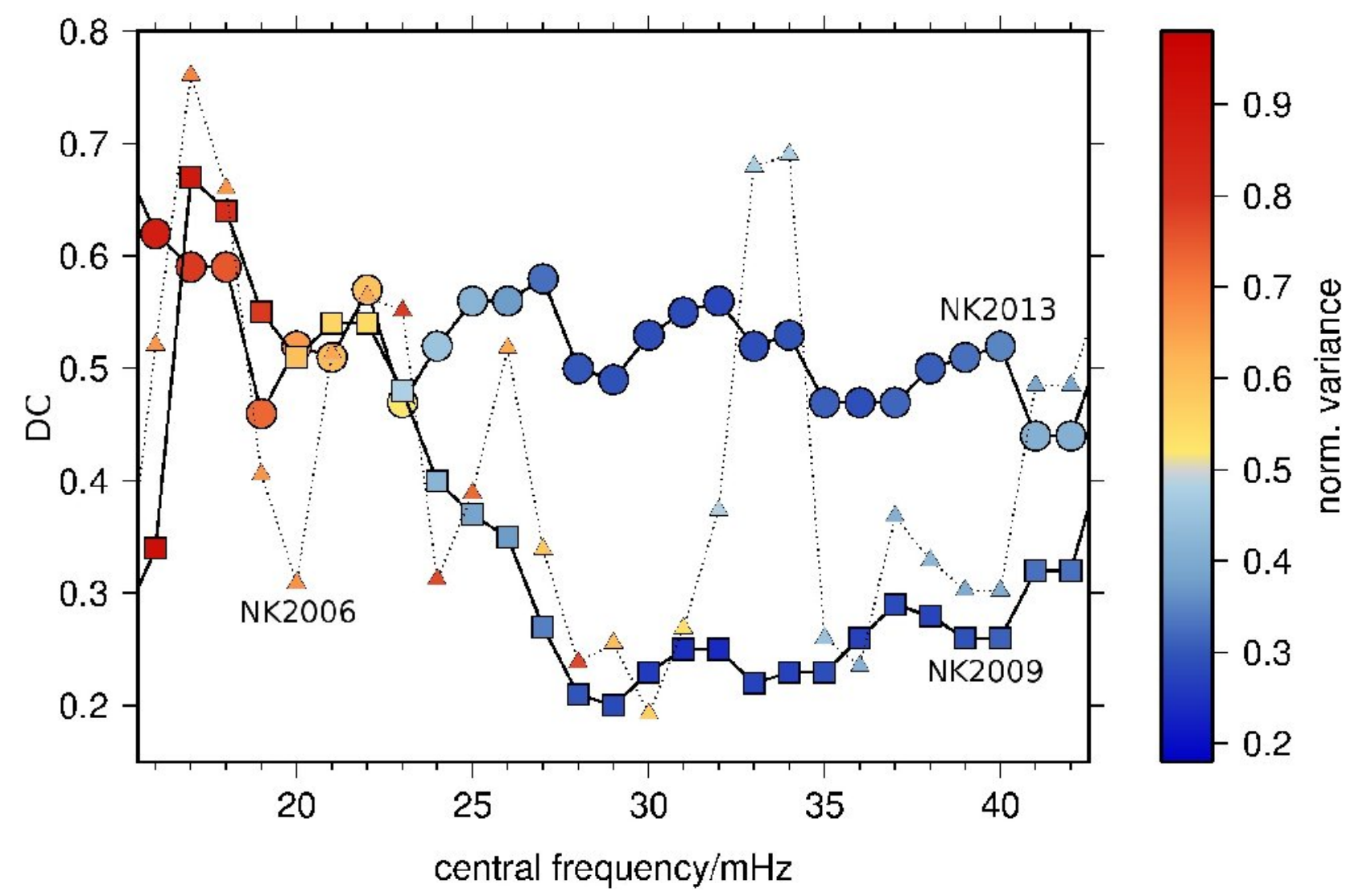

Figure 5: Portion of DC resulting from the Frequency Sensitive MTI of the 2013 (circles), 2009 (squares), and 2006 nuclear test (small diamonds). Inversion results are shown for different $8 \mathrm{mHz}-$ wide frequency pass-bands, coloured by variance $\varepsilon$ between observed $\boldsymbol{x}_{\boldsymbol{o}}$ and synthetic waveforms $\boldsymbol{x}_{\boldsymbol{s}}: \varepsilon=\left(\boldsymbol{x}_{\boldsymbol{o}}-\boldsymbol{X}_{\boldsymbol{s}}\right)^{2} / \boldsymbol{x}_{\boldsymbol{o}}{ }^{2}$. Annotations correspond to the mid-frequency of each pass-band. $D C$ is calculated by $D C=1-I S O-C L V D$ (see text). 
a) NORTH KORFA NTCL.FAR TFST 20199

(12y), Leptl: 1

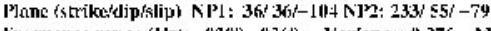

.376 AlF: 4.8
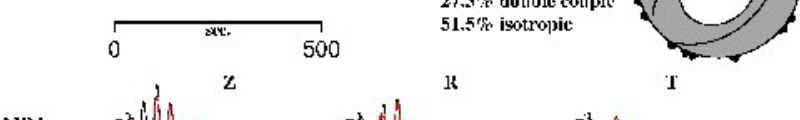
51.5 to isotion

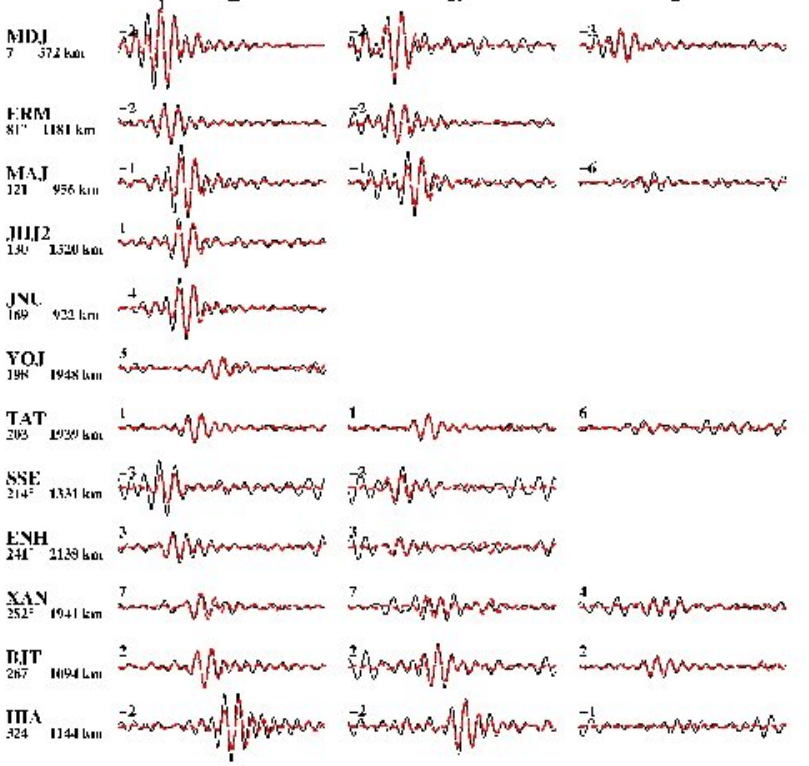

b) NORTH KORFA VCCI.EAR TFST 2013

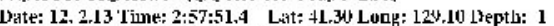

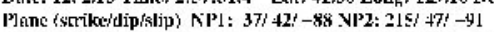

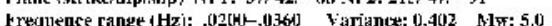
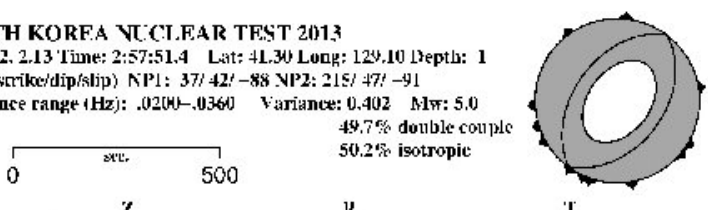

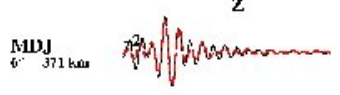

ll

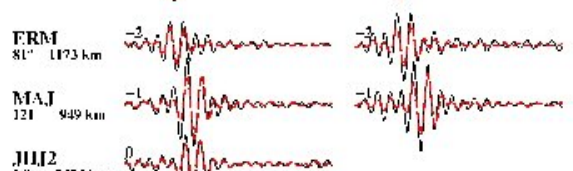
$P^{2} N$

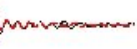

Jint 231 l.m

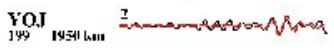

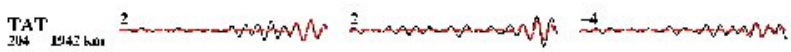

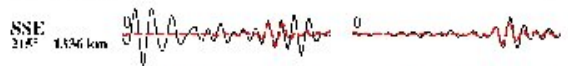

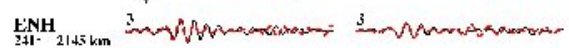

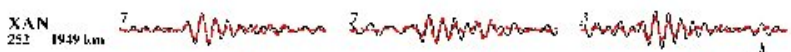

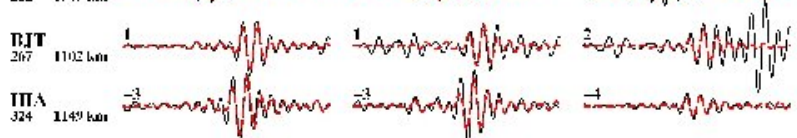

Figure 6: Final result of the Frequency Sensitive MTI for the nuclear test in 2009 and 2013 for the optimum frequency pass-band from $20 \mathrm{mHz}$ to $36 \mathrm{mHz}$ (periods $28 \mathrm{~s}$ to $50 \mathrm{~s}$ ). The inverted waveform traces are plotted as black solid lines, synthetics as red dashed lines. The illustration is as in Fig. 4. a) Source properties for the 2009 event: isotropic part $=51.5 \%, D C=27.3 \%$, strike of potential fault planes: $31^{\circ} / 43^{\circ} \mathrm{E}, \mathrm{M}_{\mathrm{W}} 4.9$. b) Source properties for the 2013 event: isotropic part $=50.2 \%$, double couple part $D C=49.7 \%$, strike of potential fault planes: $25^{\circ} / 38^{\circ} \mathrm{E}, \mathrm{M}_{\mathrm{W}} 5.1$. 


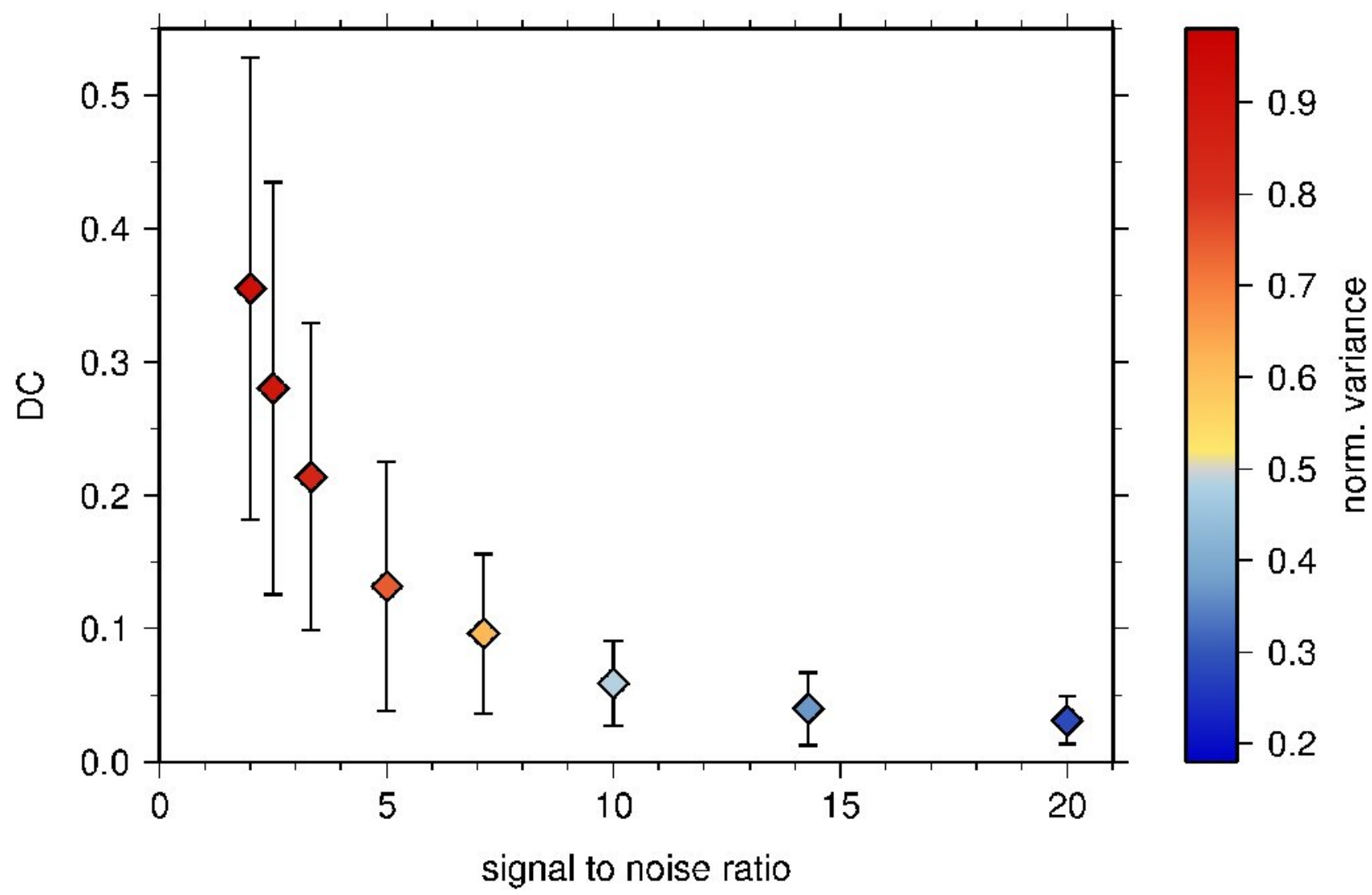

Figure 7: Portion of the DC resulting from the Frequency Sensitive MTI of synthetic waveforms that are forward calculated for a pure explosion source and biased by artificial noise with varying signal to noise ratio (frequency pass-band from $20 \mathrm{mHz}$ to $36 \mathrm{mHz}$, periods $28 \mathrm{~s}$ to $50 \mathrm{~s}$ ). Triangles are coloured by $D C$ (see text for calculation). 


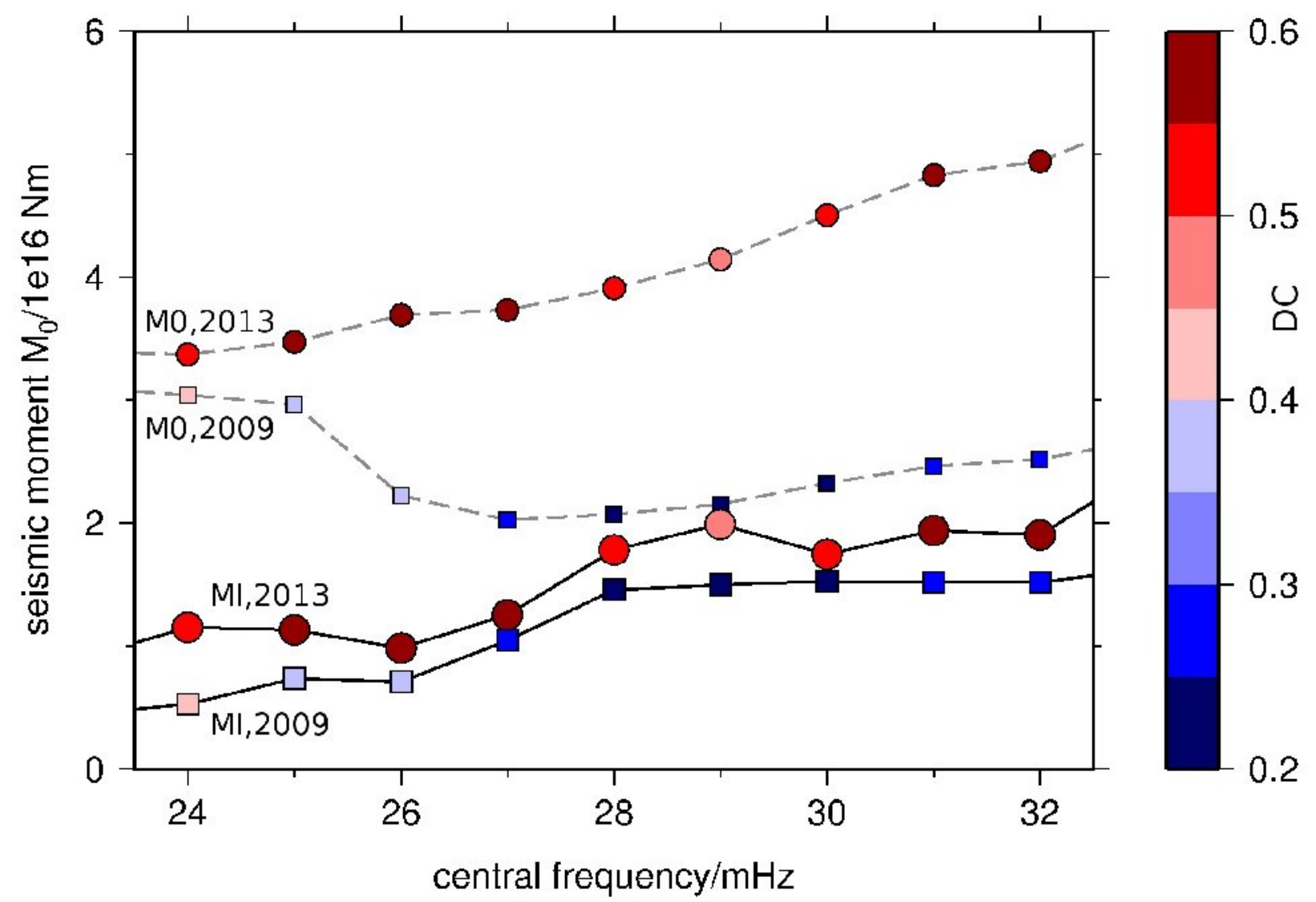

Figure 8: Seismic moments for the Frequency Sensitive MTI for the nuclear test in 2013 (circles) and 2009 (squares) for different 8 mHz-wide frequency pass-bands, coloured by DC (calculation see text). Large symbols connected by solid lines show the isotropic seismic moment $M_{I}$, smaller symbols and dashed lines represent the full seismic moment $M_{0}$. Annotations correspond to the midfrequency of each pass-band. 


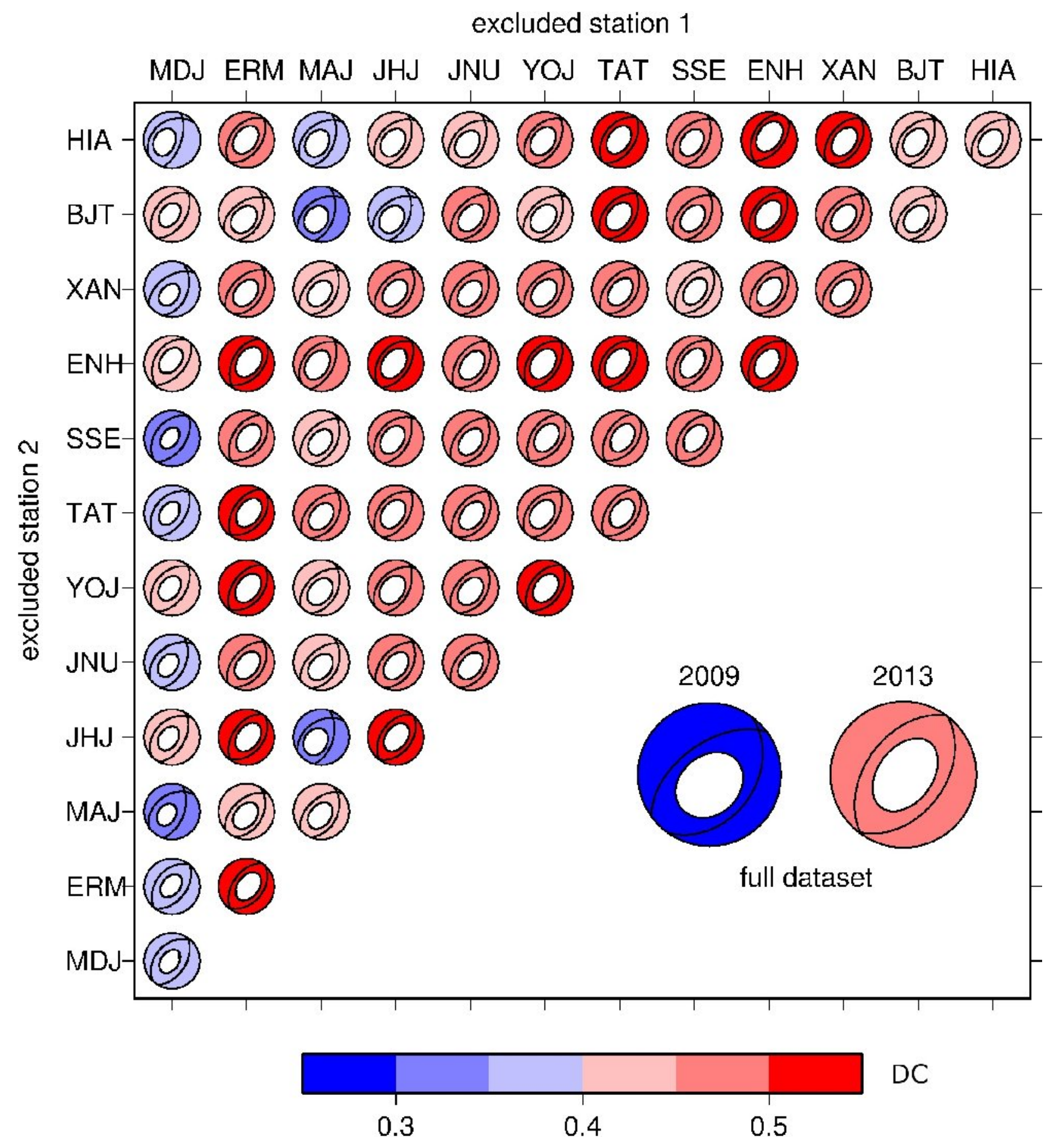

Figure 9: Jackknife test, showing the stability of DC and source mechanism for the 2013 nuclear test using the optimum frequency pass-band from $20 \mathrm{mHz}$ to $36 \mathrm{mHz}$. Coloured by $\mathrm{DC}$ (see text for calculation). Annotations correspond to the two stations (one station on the diagonal) that are excluded from the Frequency Sensitive MTI. The two large beachballs refer to the inversion result for the full dataset in 2009 and 2013, respectively (as shown in Fig. 6). 


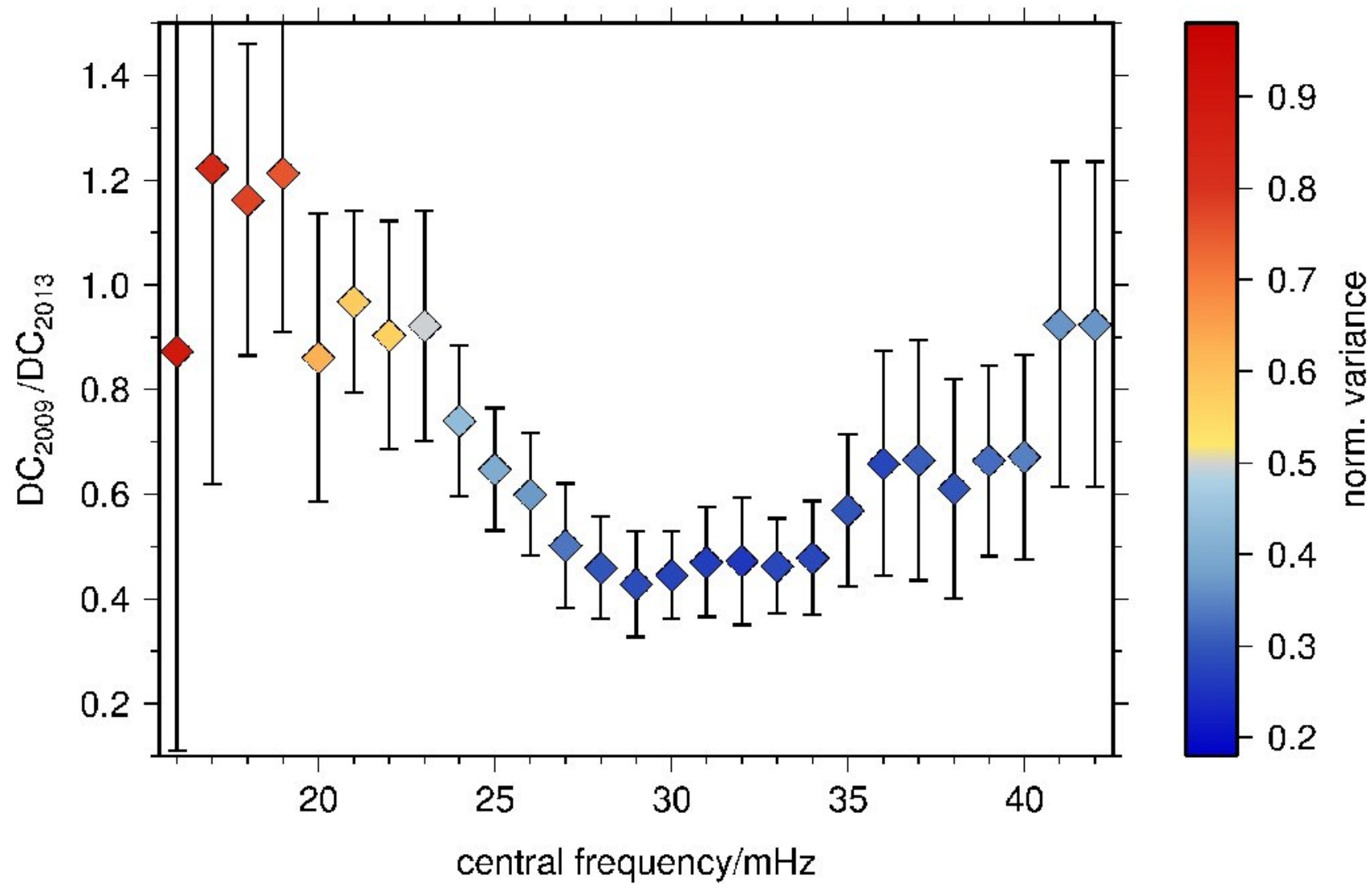

Figure 10: Averaged ratios of the $D C$ for Frequency Sensitive MTI for the nuclear tests in 2009 and 2013 for different $8 \mathrm{mHz}$-wide frequency pass-bands, coloured by variance $\varepsilon$ (see text for calculation). Averages and error bars result from the jackknife test shown in Fig. 9. Annotations correspond to the mid-frequency of each pass-band. 